\title{
Badanie złączy spawanych innowacyjnej rury kompozytowej dla energetyki
}

\author{
The welded joints research \\ of innovative composite pipe for Energy industry
}

\section{Streszczenie}

Celem prowadzonych badań była ocena jakościowa złączy spawanych ze spoinami pachwinowymi w konfiguracji rura kompozytowa - płaskownik oraz określenie wpływu energii liniowej spawania podczas spawania złączy. Złącze spawane złożone z rury kompozytowej 3R12/4L7 oraz płaskownika ze stali X6CrNi18-10 zostało poddane badaniom makroskopowym i mikroskopowym, następnie wykonano pomiar twardości metodą Vickersa, a także przeprowadzono technologiczną próbę rozciągania. Uzyskane wyniki świadczą o wysokiej jakości połączenia spawanego oraz wpływie zastosowanej energii liniowej spawania na poszczególne obszary złącza spawanego.

Słowa kluczowe: materiały bimetalowe; materiały innowacyjne; złącza spawane rury kompozytowej

\begin{abstract}
The object of study was to estimate the quality of the welded joints with fillet welds in the configuration of composite pipe - steel flat and determine the effect of arc linear energy welding joints. Welded joint consisting of a composite pipe 3R12/4L7 and flat of steel $\mathrm{X} 6 \mathrm{CrNi18-10}$ has been tested macroscopic and microscopic, then measured for hardness with Vickers method and a technological tensile test was conducted. The results show of the high quality of the welded joint and the effect of the applied arc linear energy to the different areas of the welded joint.
\end{abstract}

Keywords: bimetallic materials; innovative materials; welded joints of composite pipe

\section{Wstęp}

Rozwój stali nowej generacji jest ściśle związany z ciągle rozwijającym się przemysłem energetycznym. Obecnie energetyka w Polsce dąży do wprowadzenia kotłów o parametrach supernadkrytycznych, co bezpośrednio wpływa na zwiększenie sprawności, która może oscylować w granicach $42 \div 46 \%[1,2]$. Zwiększenie sprawności prowadzi tym samym do zmniejszenia emisji zanieczyszczeń w postaci pyłów, $\mathrm{CO}_{2}, \mathrm{SO}_{2}$ i $\mathrm{NO}_{x}$. Powyższa progresywność pozwala wykazać się nowoczesnej Inżynierii Materiałowej w zakresie projektowania i wytwarzania innowacyjnych, oraz żarowytrzymałych materiałów przeznaczonych na konstrukcje

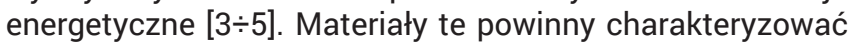
się przede wszystkim dobrą spawalnością, a także wytrzymałością na pełzanie, stabilnością strukturalną oraz odpor-

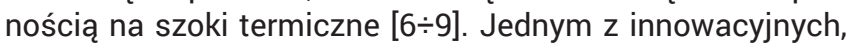
dotąd niestosowanych rozwiązań jest wykonanie materiału nowej generacji, jakim jest rura kompozytowa złożona z dwóch rodzajów stali połączonych poprzez walcowanie. Materiał nowej generacji może być stosowany wszędzie tam, gdzie warunki na zewnątrz i wewnątrz rury podczas jej pracy różnią się od siebie w sposób znaczący. Rury kompozytowe mogą być również zastosowane na wymagające elementy kotła energetycznego, jak np. ściany szczelne,

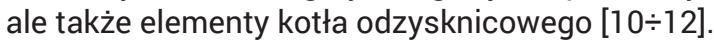

Celem niniejszego artykułu jest porównanie złączy spawanych wykonanych z różnym natężeniem prądu, a także jakościowa ocena złączy spawanych rur kompozytowych z płaskownikiem na podstawie wyników badań mikrostruktury, pomiarów twardości oraz technologicznej próby rozciągania.

\section{Materiał i metodyka badań}

Materiał do badań stanowiły złącza spawane ze spoinami pachwinowymi z rur kompozytowych i płaskownika o składzie chemicznym podanym w tablicy I. Na rurę kompozytową o średnicy $\varphi$ 50,80 mm oraz grubości g = 3,78 mm, składa się rura zewnętrzna Sandvik 3R12 (ASME 304L) o mikrostrukturze austenitycznej i rura wewnętrzna Sandvik 4L7 (ASME SA-2010A1) o mikrostrukturze ferrytyczno-perlitycznej. Grubość rury ze stali 3R12 g=1,30 mm, natomiast ze stali $4 \mathrm{~L} 7 \mathrm{~g}=3,78 \mathrm{~mm}$. Płaskownik o grubości $\mathrm{g}=6 \mathrm{~mm}$ został wykonany ze stali X6CrNi18-10. Złącza spawane złożone z rury i płaskownika spojono łukiem krytym (121) z użyciem drutu spawalniczego LNS 304L (ISO14343: S 1919 L) i topnika P2007 (ISO 14174: SA AF2 64 AC H5 2-20). Próbki do badań oznaczono zgodnie z tablicą II. Badania strukturalne prowadzono na zgładach wytrawionych w $10 \%$ kwasie

Inż. Natalia Konieczna; dr inż. Stanisław Lalik - Instytut Nauki o Materiałach Politechniki Śląskiej.

Autor korespondencyjny/Corresponding author. n.konieczna@onet.pl 
Tablica I. Skład chemiczny złącza spawanego rury kompozytowej i płaskownika, \% mas. Table I. Chemical composition of the welded joint of composite pipe and flat bar, $\%$ mass.

\begin{tabular}{|c|c|c|c|c|c|c|c|c|}
\hline Stal & C & Si & $\mathrm{Mn}$ & P & $s$ & $\mathrm{Cr}$ & $\mathrm{Ni}$ & Mo \\
\hline \multirow{3}{*}{$4 \mathrm{~L} 7$} & 0,192 & 0,274 & 0,696 & 0,007 & 0,010 & 0,076 & 0,050 & 0,018 \\
\hline & v & $\mathrm{Ti}$ & $\mathrm{Cu}$ & Al & $\mathrm{Nb}$ & N & & \\
\hline & 0,002 & 0,005 & 0,086 & 0,009 & 0,00 & 0,0069 & & \\
\hline \multirow{4}{*}{ 3R12 } & C & $\mathrm{Si}$ & $\mathrm{Mn}$ & P & $s$ & $\mathrm{Cr}$ & $\mathrm{Ni}$ & Mo \\
\hline & 0,012 & 0,36 & 1,19 & 0,023 & 0,0052 & 18,47 & 10,12 & 0,29 \\
\hline & v & $\mathrm{Ti}$ & $\mathrm{Cu}$ & Al & $\mathrm{Nb}$ & $\mathrm{N}$ & & \\
\hline & 0,050 & 0,009 & 0,35 & 0,003 & 0,01 & 0,052 & & \\
\hline \multirow{2}{*}{$\mathrm{X} 6 \mathrm{CrNi}$} & C & $\mathrm{Si}$ & $\mathrm{Mn}$ & P & $s$ & $\mathrm{Cr}$ & $\mathrm{Ni}$ & Mo \\
\hline & 0,05 & 0,35 & 1,35 & 0,018 & 0,007 & 18,20 & 10,02 & 0,11 \\
\hline
\end{tabular}

szczawiowym przy napięciu $6 \mathrm{~V}$. Obserwacje prowadzono przy pomocy mikroskopu metalograficznego Olympus GX 51, natomiast próbę twardości przeprowadzono na twardościomierzu Zwick metodą Vickersa. Technologiczną próbę rozciągania złączy spawanych złożonych z rury kompozytowej z płaskownikiem wykonano na maszynie wytrzymałościowej w celu określenia wytrzymałości na rozciąganie fragmentu panela ściany szczelnej.

\section{Wyniki i ich dyskusja}

Wyniki badań makroskopowych złączy spawanych rura kompozytowa - płaskownik przedstawiono na rysunku 1, natomiast wyniki badań mikrostrukturalnych zostały przedstawione na rysunku 2 oraz na rysunku 3 . Z analizy makrostrukturalnej złączy spawanych wynika, że w próbce o większym natężeniu prądu wynoszącym 360 A dochodzi do głębszego wtopienia spoiny (rys. 1a) niż w próbce o zastosowaniu natężenia prądu o wartości 300 A (rys. 1b). W złączu nr 1 spoiny nachodzą na siebie, natomiast w złączu nr 2 spoiny nie stykają się, są oddzielone materiałem płaskownika. Badanie mikrostruktury SWC złączy spawanych (rys. 2) pozwala stwierdzić, że w próbce nr 2 (rys. 2b) mikrostruktura jest bardziej drobnoziarnista w porównaniu do próbki nr 1 (rys. 1a), co świadczy o wpływie zastosowanego natężenia prądu i energii liniowej spawania. Co więcej na rysunku 2a można wyróżnić obszar złożony z gruboziarnistej mikrostruktury ferrytyczno-perlitycznej, strefę mikrostruktury drobnoziarnistej oraz strefę odwęgloną. Złącze spawane, w którym zastosowano niższe parametry spawania charakteryzuje się drobnoziarnistą mikrostrukturą oraz strefą odwęgloną (rys. 2b). Na podstawie analizy literatury [13] można stwierdzić, że odwęglenie jest charakterystyczne dla połączeń o odmiennym składzie chemicznym, co wynika z różnej prędkości dyfuzji węgla. Struktura strefy odwęglonej charakteryzuje się grubymi ziarnami ferrytu. Podczas długiej eksploatacji, obszar odwęglony może powodować zmniejszenie odporności na zmęczenie cieplne, a także spadek wytrzymałości na pełzanie i w konsekwencji wywołać awarie urządzeń energetycznych. Na rysunku 3a przedstawiono mikrostrukturę SWC spoiny należącej do złącza spawanego większym natężeniem prądu (złącze spawane nr 1). Wykonane obserwacje mikrostruktury potwierdzają głębokie wtopienie spoin oraz większą szerokość SWC w omawianym złączu. Szerokość SWC zależy od zastosowanej metody spawania i parametrów technologicznych. Mikrostruktura spoiny (rys. 3a i rys. 3b) ma charakterystyczną budowę dendrytyczną. Potwierdzono drobnoziarnistą mikrostrukturę ferrytyczno - perlityczną rury $4 \mathrm{~L} 7$ (rys. 3c). Z analizy mikrostruktury przedstawionej na rysunku 3d wynika, że płaskownik posiada mikrostrukturę austenityczną z pasmowym wydzieleniem węglików.
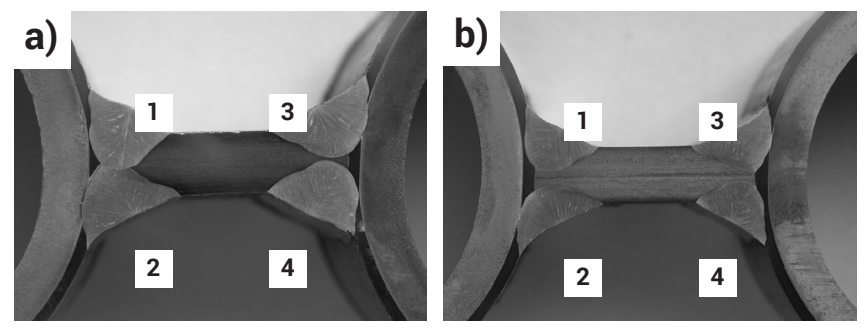

Rys. 1. a) Makrostruktura złącza spawanego nr 1 złożonego z rury 3R12/4L7 i płaskownika X6CrNi18-10 wraz z oznaczeniem spoin, b) Makrostruktura złącza spawanego nr 2 złożonego z rury 3R12/4L7 i płaskownika X6CrNi18-10 wraz z oznaczeniem spoin

Fig. 1. a) Macrostructure of the welded joint No. 1 consisting of 3R12/4L7 pipe and X6CrNi18-10 flat bar, b) Macrostructure of the welded joint No. 2 consisting of 3R12/4L7 pipe and $\mathrm{X} 6 \mathrm{CrNi18-10}$ flat bar

Z analizy wyników pomiarów twardości (tablica III) wynika, że najwyższą twardością w obu przypadkach złączy spawanych rur ze stali $3 \mathrm{R} 12 / 4 \mathrm{~L} 7$, charakteryzuje się materiał rodzimy płaskownika (próbka nr 1 - 245 HV1, próbka nr 2 - 222 HV1). Natomiast najniższą twardością charakteryzuje się SWC rury ferrytyczno-perlitycznej zarówno w próbce nr 1 (126 HV1) i próbce nr 2 (141 HV1). Zaobserwowano wpływ 
energii liniowej spawania na zmianę twardości w poszczególnych strefach złącza. Wraz z zastosowaniem większej energii liniowej spawania, spoina staje się twardsza, a tym samym mniej plastyczna, co może prowadzić do jej pęknięcia w złożonym stanie naprężeń.

Wykonane badanie technologicznej próby rozciągania na złączach spawanych złożonych z rur kompozytowych i płaskowników (rys. 4) wykazało, że zerwanie próbki nastąpiło poza złączem spawanym. Świadczy to o wysokiej wytrzymałości spoiny.
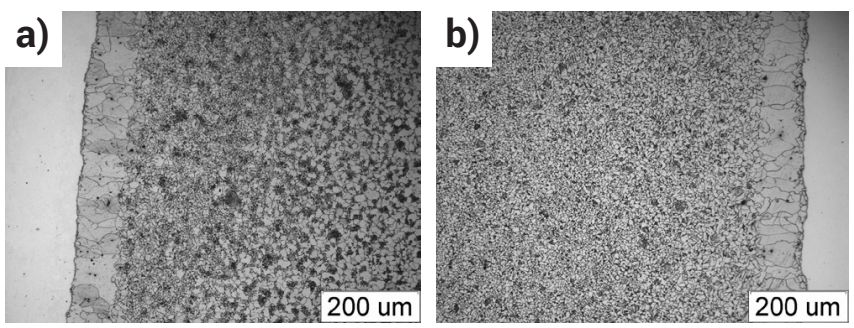

Rys. 2. a) Mikrostruktura SWC rury $4 \mathrm{~L} 7$ złącza spawanego $\mathrm{nr} 1$, b) Mikrostruktura SWC rury $4 \mathrm{~L} 7$ złącza spawanego $\mathrm{nr} 2$

Fig. 2. a) Heat affected zone microstructure of $4 \mathrm{~L} 7$ pipe welded joint No. 1, b) Heat affected zone microstructure of $4 L 7$ pipe welded joint No. 2
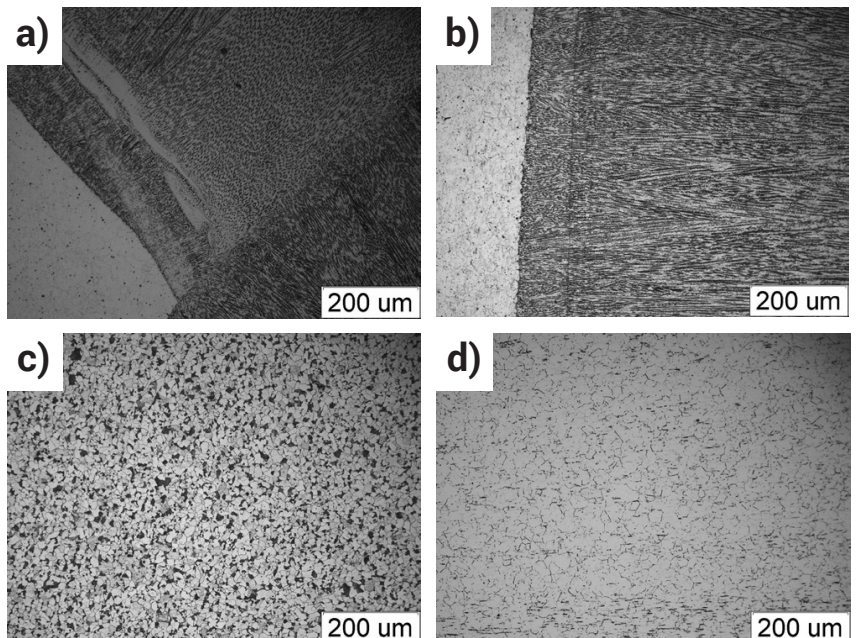

Rys. 3. a) Mikrostruktura SWC spoiny w próbce nr 1, b) Mikrostruktura SWC spoiny w próbce $\mathrm{nr} 2, \mathrm{c}$ ) Mikrostruktura rury 4L7 w próbce nr 2, d) Mikrostruktura płaskownika w próbce $\mathrm{nr} 1$

Fig. 3. a) Heat affected zone microstructure of the weld on sample No. 1, b) Heat affected zone microstructure of the weld on sample No. 2, c) Microstructure of 4L7 pipe on sample No. 2, d) Microstructure of flat bar on sample No. 1

Tablica III. Wyniki pomiarów twardości HV1 w złączu spawanym rura - płaskownik

Table III. The results of measurements of HV1 hardness in a pipe - flat bar welded joint

\begin{tabular}{|c|c|c|}
\hline $\begin{array}{c}\text { Nr próbki wraz } \\
\text { ze spoinąpomiaru twardości }\end{array}$ & $\begin{array}{c}\text { Próbka nr 1 } \\
\text { Spoina 1 }\end{array}$ & $\begin{array}{c}\text { Próbka nr 2 } \\
\text { Spoina 1 }\end{array}$ \\
\hline Materiał rodzimy płaskownika & $245,230,237$ & $216,212,222$ \\
\hline Sfera wpływu ciepła płaskownika & $245,231,230$ & $191,187,200$ \\
\hline Spoina & $224,227,215$ & $167,166,174$ \\
\hline Sfera wpływu ciepła rury austenitycznej & $236,229,228$ & $199,201,199$ \\
\hline $\begin{array}{c}\text { Materiał rodzimy rury austenitycznej } \\
\text { Sfera wpływu ciepła rury } \\
\text { ferrytyczno-perlitycznej }\end{array}$ & $221,225,228$ & $198,212,212$ \\
\hline $\begin{array}{c}\text { Materiał rodzimy rury } \\
\text { ferrytyczno-perlitycznej }\end{array}$ & $189,193,199$ & $208,191,203$ \\
\hline
\end{tabular}
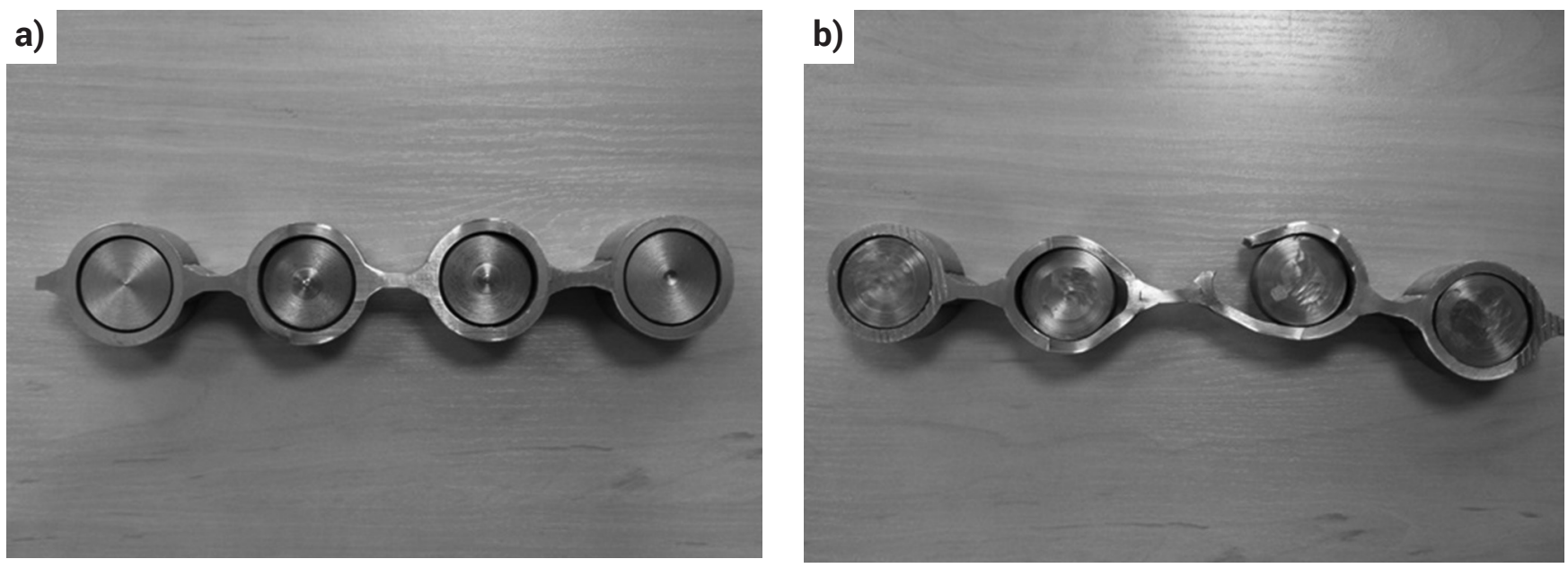

Rys. 4. Widok złącza spawanego a) przed technologiczną próbą rozciągania, b) po technologicznej próbie rozciągania

Fig. 4. View of welded joint a) before technological tensile test, b) after technological tensile test 


\section{Podsumowanie}

Na podstawie przeprowadzonych badań metalograficznych, analizy twardości oraz technologicznej próby rozciągania złącza spawanego rury kompozytowej 3R12/4L7 i płaskownika ze stali X6CrNi18-10, a także analizy literatury dotyczącej złączy spawanych można sformułować następujące wnioski:

- Złącza spawane oznaczone jako nr 1 i nr 2 mają poprawną budowę geometryczną i są wolne od niezgodności spawalniczych.

- Przeprowadzone badania mikrostruktury pozwalają stwierdzić, że płaskownik charakteryzuje się mikrostrukturą austenityczną, natomiast spoina ma budowę dendrytyczną.

- W obu przypadkach złącza spawanego (nr 1 i nr 2) z rury 3R12/4L7 oraz płaskownika X6CrNi18-10 zaobserwowano najwyższą twardość w materiale rodzimym płaskownika, a najmniejszą w materiale rodzimym stali ferrytyczno-perlitycznej.

- Zwiększenie energii liniowej spawania wpływa na zmniejszenie twardości w poszczególnych strefach złącza spawanego.

- Przeprowadzona technologiczna próba rozciągania złącza spawanego potwierdziła wysoką wytrzymałość i jakość połączeń; zerwanie próbki nastąpiło poza złączem spawanym.

\section{Literatura}

[1] A. Hernas, J. Pasternak, S. Fudali, J. Witkowski, „Właściwości technologiczne nowych materiałów przeznaczonych do budowy kotłów na parametry nadkrytyczne", Praca zbiorowa pod red. A. Hernasa: Procesy niszczenia oraz powłoki ochronne stosowane w energetyce, s.255-274, 2015.

[2] A. Hernas, „Żarowytrzymałość stali i stopów”, Wydawnictwo Politechniki Śląskiej, Gliwice, 1999.

[3] S. Lalik, G. Niewielski, „Spawanie stali przeznaczonych na elementy nadkrytyczne kotłów”, Inżynieria Materiałowa, nr 6, s.727-728, 2003.

[4] E. Tasak, A. Ziewiec, "Spawalność materiałów konstrukcyjnych. Tom 1. Spawalność stali", Wydawnictwo JAK Kraków, 2009.

[5] M. Łomozik, „Żarowytrzymałe stale konstrukcyjne dla przemysłu energetycznego - wczoraj i dziś", Biuletyn Instytutu Spawalnictwa, nr 5, s.52-53, 2013.

[6] E. Tasak, „Metalurgia spawania”, Wydawnictwo JAK, Kraków, 2008.

[7] J. Pasternak, S. Fudali, A. Hernas, M. Staszewski, "Stale austenityczne do zastosowań w kotłach o parametrach nadkrytycznych", Energetyka, Zeszyt tematyczny, nr 18, s.100-103, 2008.

[8] P. Jamrozik, M. Sozańska, J. Pasternak, „Właściwości mechaniczne złączy spawanych ze stali Sanicro 25 oraz stopu HR6W", Przegląd Spawalnictwa, nr 10, s. 39-45, 2013.

[9] P. Urbańczyk, J. Słania, G. Golański, M. Matusik, „Wpływ pełzania na uszkodzenia złącza spawanego rurociągu pary świeżej”, Przegląd Spawalnictwa, nr 4, s. 23-31, 2014

[10] J. Adamski, A. Balcerzyk, S. Lalik, „Badania przemysłowe gazoszczelnych ścian rurowych i wężownic ze stali nowej generacji”, Energetyka, nr 10, s.645-647, 2015.

[11] Sandvik 3R12/4L7, "Composite tubes for recovery boilers and other boiler applications", Sandvik Materials Technology, 2012.

[12] M. Blicharski, „Zmiany mikrostruktury w połączeniach spawanych różnoimiennych materiałów stosowanych w energetyce", Przegląd Spawalnictwa, nr 3, s. 2-13, 2013

[13] E. Tasak, A. Ziewiec, K. Ziewiec, „Problemy występujące przy spawaniu i naprawie spoin stali różnorodnych", Archiwum Hutnictwa, nr 21, s.221226, 2006. 